\title{
Interventions in the neonatal environment in rats and their relationship to behavior in adulthood and maternal behavior
}

\author{
Márcia Scherem de Azevedo ${ }^{1}$, Fabiana Leopoldo de Souza ${ }^{1}$, Márcio Vinícius Fagundes Donadio², \\ Aldo Bolten Lucion ${ }^{1}$ and Márcia Giovenardi ${ }^{3}$ \\ 1 Universidade Federal do Rio Grande do Sul, Brazil \\ 2 Pontifícia Universidade Católica do Rio Grande do Sul, Brazil \\ 3 Universidade Federal de Ciências da Saúde de Porto Alegre, Brazil
}

\begin{abstract}
The objective of this study was to assess the role of environmental/nest components and maternal behavior after several neonatal interventions on subsequent behavioral responses. Male Wistar rats were subjected to different neonatal interventions and were later evaluated for innate fear-like behavior in adulthood. The experimental groups included nonhandled (i.e., animals were not touched), handled (i.e., animals were separated from their mother, removed from the nest, and handled for $10 \mathrm{~min} /$ day), brief maternal separation (i.e., the mother was removed from the homecage for $10 \mathrm{~min} /$ day, and the pups remained in their cages without being touched), and tactile stimulation (i.e., the mother was removed from the homecage, and pups were stimulated with a brush for 10 min/day within the nest). The mother's behavior was recorded during the neonatal period, and the male pups were later tested in the open field as adults. The results revealed that only mothers whose pups were handled had an increase in the duration of licking behavior compared with the other groups. In the open field test, we observed decreased behavioral innate fear-like responses in male adults in the handled and brief separation groups compared with the others groups. Our results confirm that interventions during the neonatal period cause stable behavioral changes (decreased innate fear) in adulthood and that absent or excessive tactile stimulation appears to be an important factor. Both repeated disruption of the mother-infant relationship and withdrawal from the environment/nest are factors that exert profound effects on the development of the animals. Keywords: brief separation, neonatal handling, tactile stimulation, innate fear, rats.
\end{abstract}

Received 21 September 2009; received in revised form 9 March 2010; accepted 18 March 2010. Available on line 26 June 2010

\section{Introduction}

The neonatal period is a phase when an animal's first social connections are formed (Scott, 1962). Normal interactions in the mother-pup relationship are important for the proper growth and development of mammals (Pauk, Khun, Field, \& Schanberg, 1986). Maternal behavior in rats consists of various integrated elements related to the nutrition and care of the offspring. These behaviors either directly involve the pups (e.g., lactation, licking, searching for pups) or do not directly involve the

Márcia Scherem de Azevedo, MSc Programa de PósGraduação em Ciências Biológicas: Fisiologia Laboratório de Neuroendocrinologia do Comportamento Universidade Federal do Rio Grande do Sul - UFRGS Porto Alegre/Brasil. Fabiana Leopoldo de Souza, Laboratório de Neuroendocrinologia do Comportamento, Departamento de Fisiologia, Instituto de Ciências Básica da Saúde, Universidade Federal do Rio Grande do Sul, Porto Alegre, RS, Brazil. Márcio Vinícius Fagundes Donadio, Laboratório de Biofísica Celular e Inflamação, Departamento de Ciências Fisiológicas e Faculdade de Enfermagem, Nutrição e Fisioterapia, Pontifícia Universidade Católica do Rio Grande do Sul, Porto Alegre, RS, Brazil. pups (e.g., building nests, maternal aggression) (Numan $\&$ Insel, 2003). In rats, mothers spend up to $85 \%$ of their total time during the lactation period in the nest with their pups, feeding or licking their litter (Grota \& Ader, 1969; Stern \& Johnson, 1990).

Several studies have shown that the neonatal environment can have a decisive influence on animal development, inducing behavioral, neuroendocrine, and neural changes that endure throughout life (Levine, 2001; Liu, Caldji, Sharma, Plotsky, \& Meaney, 2000; Meaney et al., 1996; Padoin, Cadore, Gomes, Barros, \& Lucion,

Aldo Bolten Lucion, Laboratório de Neuroendocrinologia do Comportamento, Departamento de Fisiologia, Instituto de Ciências Básica da Saúde, Universidade Federal do Rio Grande do Sul, Porto Alegre, RS, Brazil. Márcia Giovenardi, Departamento de Ciências Básicas da Saúde, Universidade Federal de Ciências da Saúde de Porto Alegre, Porto Alegre, RS, Brazil. Correspondence regarding this article should be directed to: Márcia Scherem de Azevedo, Rua Sarmento Leite, 500, $2^{\circ}$ andar, Laboratório 11, Departamento de Fisiologia, Instituto de Ciências Básica da Saúde, Universidade Federal do Rio Grande do Sul, Porto Alegre, RS, Brazil, CEP 90050170.E-mail: marciascherem@yahoo.com.br 
2001). Previous studies demonstrated that pups subjected to neonatal handling, which involves concomitant brief maternal separation and tactile stimulation of the pups, exhibit less fear-like behavior as adults in novel or adverse environments compared with adults that were not subjected to neonatal handling (Bodnoff, SuranyiCadotte, Quirion, \& Meaney, 1987; Fernandez-Teruel, Eschorihuela, Driscoll, Tobena, \& Battig, 1991; Levine, Haltmeyer, Karas, \& Denenberg, 1967; Madruga, Xavier, Achaval, Sanvitto, \& Lucion, 2006). These animals also exhibit important reproductive and neural changes (Gomes, Frantz, Sanvitto, Ancelmo-Franci, \& Lucion, 1999; Gomes et al., 2005; Lucion, Pereira, Winkelman, Sanvitto, \& Anselmo-Franci, 2003). Liu et al. (1997) proposed that long-lasting behavioral and neuroendocrine changes can be explained by alterations in the mother-pup relationship and an increase in maternal behavior after pups return to the nest after the neonatal handling procedure (Liu et al., 1997; Macri, Mason, \& Wurbel, 2004). Mothers whose pups were handled for 15 minutes during the neonatal period exhibit increased licking and arched-back feeding behaviors compared with mothers of nonhandled pups (Francis, Champagne, Liu, \& Meaney, 1999; Liu et al., 1997).

Studies have shown that neonatal separation from the mother, in which male pups were removed from the nest for 3 hours per day, increases corticosterone secretion in response to stress and increases anxiety levels when exposed to novel environments as adults (Kalinichev, Easterling, Plotsky, \& Holtzman, 2002; Matthews, Wilkinson, \& Robbins, 1996). The tactile stimulation procedure prevents or reverses the decrease in growth hormone and the increase in corticosterone secretion in pups that were separated during the neonatal period (Schanberg, Evoniuk, \& Kuhn, 1984).

A previous study conducted in our laboratory (Benetti, de Araújo, Sanvitto, \& Lucion, 2007) demonstrated that mothers of rats handled inside and outside of the nest during the neonatal period (i.e., half of the litter was exposed to a novel environment, and the other half remained in the nest) do not exhibit changes in maternal behavior towards their pups. However, as adults, males that were handled outside of the nest exhibited less fear in the open field and reduced sexual behavior compared with pups handled inside the nest, indicating that the environment/nest plays a key role in development and later responses in adulthood.

However, few studies have explored the reasons why such interventions during the neonatal period can induce significant behavioral changes in adulthood. Thus, the objective of the present study was to assess the role of the environment/nest component and maternal behavior after several neonatal interventions in later behavioral responses. Male Wistar rats were subjected to different neonatal interventions and were later evaluated for innate fear-like behavior in adulthood. The assessment of these components (environment/nest and maternal behavior) may explain the behavioral changes observed in these animals in adulthood. Four different experimental groups were used: nonhandled, handled, brief maternal separation, and tactile stimulation.

\section{Methods}

\section{Animals}

Primiparous pregnant Wistar rats $(n=59)$, aged 75 days and weighing $240 \pm 20 \mathrm{~g}$, were obtained from the Universidade do Vale do Rio dos Sinos. After parturition, the females were divided into four experimental groups according to which intervention was carried out with the pups: nonhandled, handled, brief maternal separation, and tactile stimulation. At 21 days of age, the pups were weaned, and males were housed five per cage until adulthood (90 days). One male from each litter $(n=59)$ was used for evaluation in the open field test.

All animals were housed in a temperature-controlled room $\left(22 \pm 1^{\circ} \mathrm{C}\right)$ under a $12 \mathrm{~h} / 12 \mathrm{~h}$ light/dark cycle, with lights off at 4:00pm. All animals had free access to water and food (Nuvilab Cr2, Colombo, Brazil) for the entire study period. All of the experiments were conducted according to the National Institutes of Health Guide for the Care and Use of Laboratory Animals and the Brazilian School of Animal Experimentation (COBEA) guidelines.

\section{Neonatal intervention}

Pregnant rats $(n=59)$ were individually placed in transparent acrylic boxes, and the day of parturition was monitored and designated day 0 . On the day following parturition, the litters were randomly standardized into eight pups each, without consideration of the sex of the pups. The litters undergoing one type of neonatal intervention until postnatal day 10 were allocated to the following groups. In the nonhandled group $(n=$ 15), animals were not touched by researchers or by the vivarium staff during the first 10 postnatal days. In the handled group $(n=15)$, animals were separated from the mother and handled for 10 minutes per day for the first 10 postnatal days. The handling procedure consisted of removing the mother from the homecage and placing it in a separate room. The pups remained in the colony room, separated from the nest, and were handled for 10 minutes per day by a latex-gloved researcher as described in previous studies (Gomes et al., 1999, 2005; Padoin et al., 2001; Raineki et al., 2008, 2009; Severino et al., 2004). The pups were then immediately returned to their homecages, and the mother was then returned to the cage (Severino et al., 2004). In the brief separation group $(n=14)$, the mother was removed from the homecage and placed in another room for 10 minutes, and the pups remained in their cages without undergoing any other intervention (Macri et al., 2004). In the tactile 
stimulation group $(n=15)$, the mother was removed from the homecage and placed in another room for 10 minutes each day. The pups remained in the nest and were vigorously stimulated with a soft bristled brush on their backs during their mother's absence for the first 10 postnatal days (Pauk et al., 1986). After the stimulation of each litter, the brush was washed with soap and dried.

All experimental procedures began on the day following parturition (day 1) and were performed during the light cycle at random times (Raineki et al., 2008, 2009; Severino et al., 2004). Cleaning of the homecages began on postnatal day 11 .

\section{Maternal behavior}

After the interventions, the mothers' behavior ( $n=$ 59 ) with their litters in the homecage was video recorded during the light cycle for 30 minutes on postnatal day 1, 5, and 10. The behaviors observed included the following: mother licking any pup (body surface or anogenital region), mother nursing pups in arched-back posture, gathering the pups, and remaining in the nest (Moore, 1992; Stern \& Johnson, 1990). Maternal behavior data were expressed as the mean of the three recordings (postpartum day 1, 5, and 10) for each rat in each group.

\section{Open field test}

The male pups were weaned on day 21. On day 90 , they were tested in the open field as previously described (Blanchard \& Blanchard, 1988). The open field consisted of a $1 \mathrm{~m}^{2}$ wooden box with $50 \mathrm{~cm}$ high walls. The arena was surrounded by $30 \mathrm{~cm}$ high walls and divided into 25 equal squares painted on the floor, with 16 squares in the lateral zone and nine squares in the central zone of the arena. The experimental procedure consisted of placing a rat in a random corner of the open field and video recording its activity for 5 minutes. The test was performed at 10:00am during the light cycle under natural light with the room's lights turned on. Three test-specific behaviors were assessed: total locomotion (i.e., number of line crossings), number of visits to the central zone, and time spent in the central zone (Benetti et al., 2007; Madruga et al., 2006). At the end of the test, the rat was removed from the arena, and the floor was washed with $50 \%$ alcohol and wiped dry. Innate fear-like behavior was determined by evaluating locomotor activity in the central zone of the open field (Benetti et al., 2007; Madruga et al., 2006). Duration and latency parameters were included for all of the aforementioned behaviors.

\section{Behavioral analysis}

All behavioral analyses from this study were recorded on VHS tape and later evaluated using Noldus Observer software (Noldus Information Technology, Wageningen, The Netherlands).

\section{Statistical analysis}

Mean $( \pm$ SEM) latency and duration were compared between experimental groups using one-way analysis of variance (ANOVA) followed by the Newman-Keuls post hoc test. Pearson's correlation analysis was performed for licking and open field behaviors. When interpreting the results, values of $p<.05$ were considered statistically significant.

\section{Results}

Figure 1a shows the duration of licking behavior. One-way ANOVA revealed a significant increase in the duration of licking behavior in the handled group compared with the other groups $\left(F_{3,55}=4.61, p=\right.$
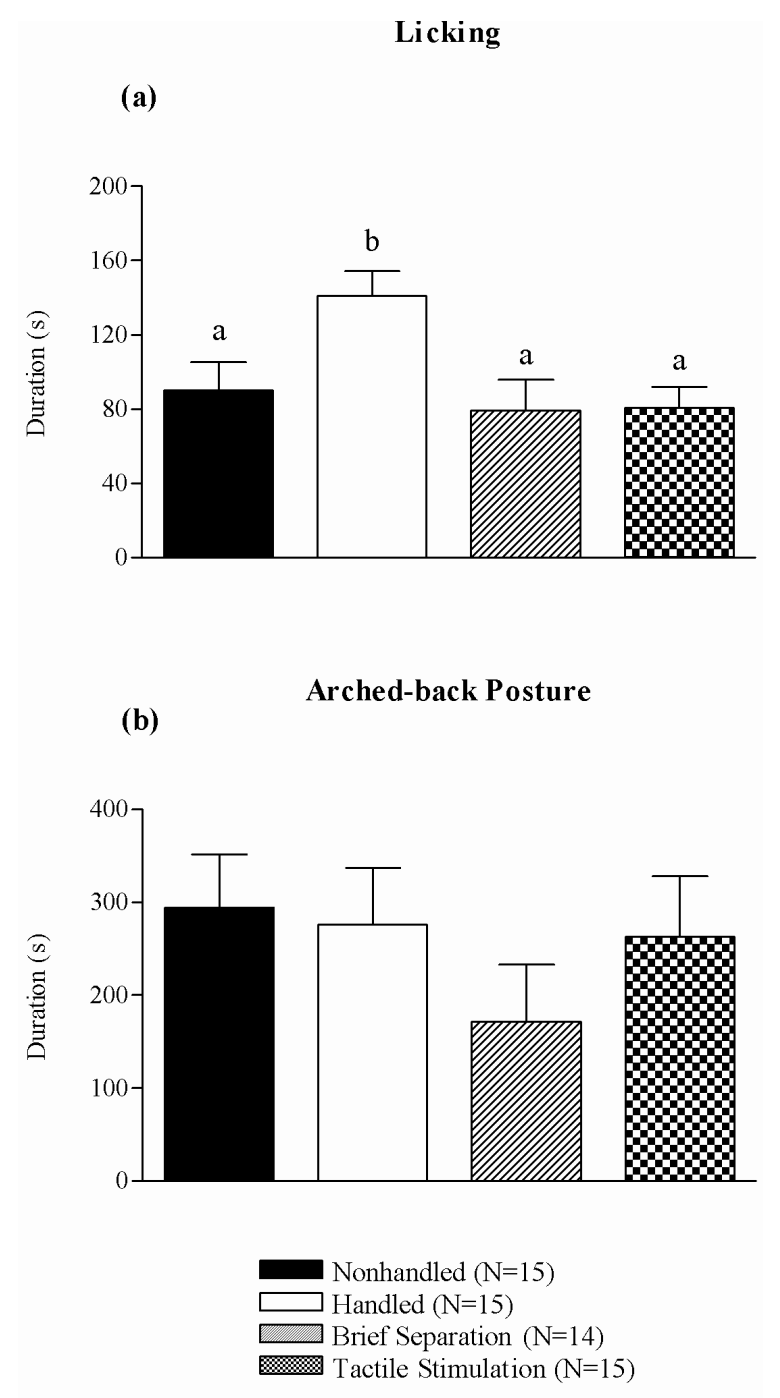

Figure 1. Mean ( \pm SEM) licking behavior (a) and archedback posture (b) in female rats whose pups were subjected to an intervention during the neonatal period. Each lactating rat was analyzed for 30 minutes after the experimental procedure. The number of animals (N) is shown in parentheses. Oneway ANOVA was used, followed by the Newman-Keuls post hoc test. Significant differences $(p<.05)$ between groups are indicated by different letters ( $a$ and $b$ ), whereas the same letters indicate no difference. 
$.005)$. Figure $1 \mathrm{~b}$ indicates no significant difference in nursing behavior with an arched-back posture between groups $\left(F_{3,55}=.77, p=.51\right)$.

No significant differences were observed in the amount of time the mother remained in the nest between the handled, brief separation, and tactile stimulation groups compared with the nonhandled group $(806.5 \pm 85.26 \mathrm{~s}$, $566.2 \pm 107.8 \mathrm{~s}, 753.9 \pm 83.96 \mathrm{~s}, 818 \pm 115 \mathrm{~s}$, respectively; mean \pm SEM). No significant differences were observed between groups in the time mothers spent gathering pups in the nests $(472.2 \pm 681.2 \mathrm{~s}, 422.4 \pm 601.8 \mathrm{~s}, 486.8 \pm 85.2$ $\mathrm{s}, 322.9 \pm 56.24 \mathrm{~s}$, respectively; mean $\pm \mathrm{SEM})$.

Figure $2 \mathrm{a}$ shows a significant reduction in the latency $\left(F_{3,55}=5.22, p=.003\right)$ and Figure $2 \mathrm{~b}$ shows a significant increase in the duration $\left(F_{3,55}=3.42, p=.02\right)$ for entering

\section{(a)}

\section{Open-field Center}

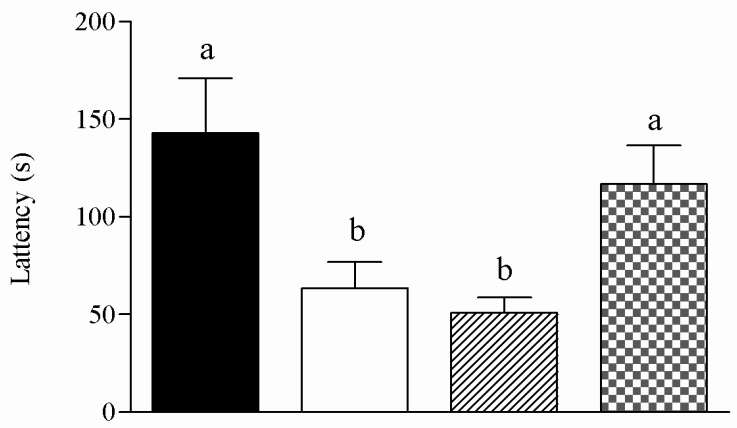

(b)

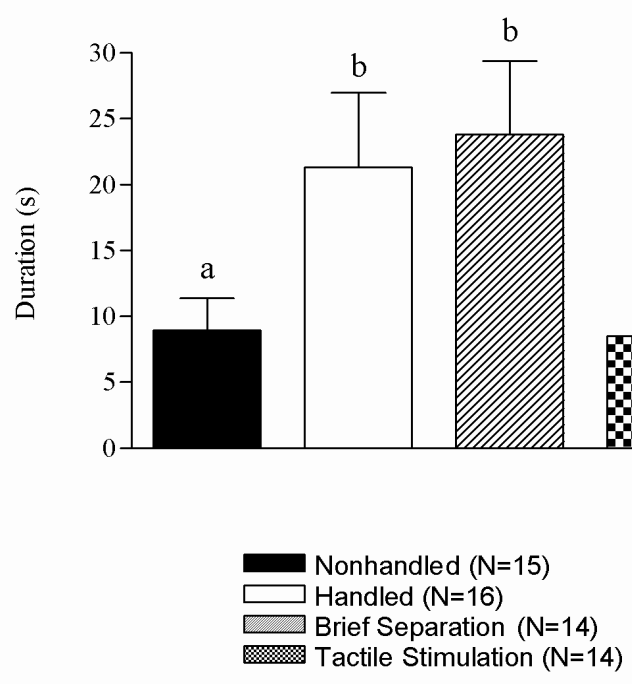

Figure 2. Mean ( \pm SEM) latency (a) and duration (b) of entries in the central zone of the open field test in rats subjected to an intervention during the neonatal period. Each rat was analyzed for 5 minutes. The number of animals $(\mathrm{N})$ is shown in parentheses. One-way ANOVA was used, followed by the Newman-Keuls post hoc test. Significant differences $(p<.05)$ between groups are indicated by different letters ( $a$ and $b$ ), whereas the same letters indicate no difference. the central zone of the open field in handled and brief separation groups compared with nonhandled and tactile stimulation groups. However, no significant correlations were found between licking behavior and either the latency or duration to enter the central zone of the open field in the handled ( $r=.06$ and $r=.07$, respectively) and brief separation ( $r=-.32$ and $r=.01$, respectively) groups.

No significant difference was observed in the frequency of rearing behavior in the handled, brief separation, and tactile stimulation groups compared with the nonhandled group $(19.13 \pm 2.2,19.64 \pm 1.7$, $15.79 \pm 1.7,16.07 \pm 2.5$, respectively; mean \pm SEM). Moreover, no significant differences were observed in scanning behavior $(4.25 \pm 1.2,4.4 \pm 1.3,1.64 \pm .5,3.6 \pm$ 1.2 , respectively; mean $\pm \mathrm{SEM}$ ).

\section{Discussion}

The present study demonstrated that environmental variations during the neonatal period generate stable behavioral changes in adulthood that may or may not be associated with modifications in maternal behavior. The neonatal handling model used in the present study consists of briefly removing pups from the nest followed by tactile stimulation. Our results showed that when the pups were returned to their nests, an increase in mother licking behavior was observed. Additionally, as adults, the animals exhibited less fear-like behavior than those that were not subjected to maternal separation and tactile stimulation. These results are consistent with previous reports, in which animals handled during the neonatal period exhibited less fear-like behavior when exposed to the open field test (Madruga et al., 2006; Padoin et al., 2001).

However, in the brief separation group (in which the mother was briefly removed from the homecage and the litter remained in the environment), no change in maternal behavior was observed. When these pups became adults, they exhibited reduced fear-like behavior, a result similar to that found in the handled group. Our results are consistent with Macri et al. (2004), which used a similar methodology. In this study, no changes were observed in maternal behavior (i.e., licking and feeding with an arched back) compared with the control group. However, a reduction in fear-like behavior was observed in adult rats in the open field test.

In rats, the main tactile stimulation that pups receive from the mother is licking of the body and anogenital region, a behavior as important as feeding (Van Oers, de Kloet, \& Levine, 1999). Several studies emphasize the importance of the mother-pup relationship during the neonatal period for the full development of the offspring (Champagne, Francis, Mar, \& Meaney, 2003; Pauk et al., 1986). Changes in the mother's behavioral patterns can alter both the plasticity of the pups' nervous systems and their behavior (Van Oers et al., 1999). Some studies (Champagne et al., 2003; 
Liu et al., 1997, 2000; Meaney et al., 1996) suggest that the behavioral changes observed in adult rats handled during the neonatal period are attributable to the mother's increased licking behavior. However, the present results reveal that the mothers that were briefly separated from their pups exhibited no significant changes in maternal behavior, but their offspring had behavioral changes in adulthood similar to the handled group. These results indicate that licking behavior is not the only important factor; the absence of this behavior over a specific period also plays a role. Although the maternal behaviors analyzed in the present study are important, other behaviors could also play a role in the behaviors exhibited in adulthood. The neonate's environment (e.g., the nest and homecage) is also a fundamental factor for normal development (Benetti et al., 2007). Our results suggest that removal from the nest might be the most critical factor for changes in maternal behavior. The groups whose intervention did not involve removal of the litter from their environment (separation and tactile stimulation) displayed maternal behavior similar to the control group.

In the tactile stimulation group, in which the mother was taken from the nest and the pups remained in their environment and were stimulated, no change in maternal behavior or fear-like behavior was observed in adulthood compared with the nonhandled group. A previous study (Pauk et al., 1986) found that tactile stimulation with a brush reversed the effects caused by a 2 hour neonatal separation per day, which led to reduced growth hormone levels and reduced ornithine decarboxylase in heart tissue. These previous results, combined with those of the present study, suggest that this tactile stimulation procedure is not an adverse stimulus and may substitute for the role played by the mother by mimicking the mother's behavior. The behavioral changes in adulthood secondary to interventions during the neonatal period appear to be related to an appropriate balance of tactile stimuli during this period. Excessive stimulation (i.e., an increase in maternal behavior in the handled group) and a lack of stimulation for a specific period (i.e., brief separation) induced stable changes, whereas tactile stimulation, which mimics normal maternal behavior, prevented these changes despite the period of separation from the mother.

A stable mother-pup interaction and neonatal environment/nest appear to be critical for normal growth and development in rats. Our results confirm that interventions during the neonatal period cause stable behavioral changes (decreased innate fear) in adulthood and that absent or excessive tactile stimulation may be an important factor. We can conclude that both repeated disruption of the mother-infant relationship and withdrawal from the environment/nest are factors that exert profound effects on the development of the animals.

\section{Acknowledgements}

We thank Dirson J. Stein for carefully handling the animals and João F. Silveira for his support in the experiments. This study received financial support from FAPERGS, FAPESP, and CNPq.

\section{References}

Benetti, F., deAraújo, P.A., Sanvitto, G.L., \& Lucion, A.B. (2007). Effects of neonatal novelty exposure on sexual behavior, fear, and stress-response in adult rats. Developmental Psychobiology, 49, 258-264.

Blanchard, D.C., \& Blanchard, R.J. (1988). Ethoexperimental approaches to the biology of emotion. Annual Review of Psychology, 39, 43-68.

Bodnoff, S.R., Suranyi-Cadotte, B., Quirion, R., \& Meaney, M.J. (1987). Postnatal handling reduces novelty-induced fear and increases $\left[{ }^{3} \mathrm{H}\right]$ flunitrazepam binding in rat brain. European Journal Pharmacology, 144, 105-107.

Champagne, F.A., Francis, D.D., Mar, A., \& Meaney, M.J. (2003). Variations in maternal care in the rat as a mediating influence for the effects of environment on development. Physiology and Behavior, 79, 359-371.

Fernandez-Teruel, A., Eschorihuela, R.M., Driscoll, P., Tobena, A., \& Battig, K. (1991). Infantile (handling) stimulation and behavior in young Roman high- and low-avoidance rats. Physiology and Behavior, 50, 563-565.

Francis, D.D., Champagne, F.A., Liu, D., \& Meaney, M.J. (1999). Maternal care, gene expression, and the development of individual differences in stress reactivity. Annals of the New York Academy of Sciences, 896, 66-84.

Gomes, C.M., Raineki, C., de Paula, R.P., Severino, G.S., Helena, C.V., Anselmo-Franci, J.A., Franci, C.R., Sanvitto, G.L., \& Lucion, A.B. (2005). Neonatal handling and reproductive function in female rats. Journal of Endocrinology, 184, 435-445.

Gomes, C.M., Frantz, P.J., Sanvitto, G.L., Ancelmo-Franci, J.A., \& Lucion, A.B. (1999). Neonatal handling induces anovulatory estrous cycles in rats. Brazilian Journal of_Medical and Biological Research, 32, 1239-1242.

Grota, L.J., \& Ader, R. (1969). Continuous recording of maternal behaviour in Rattus novergicus. Animal Behaviour, 17, 722-729.

Kalinichev, M., Easterling, K.W., Plotsky, P.M., \& Holtzman, S.G. (2002). Long-lasting changes in stress-induced corticosterone response and anxiety-like behaviors as a consequence of neonatal maternal separation in Long-Evans rats. Pharmacology Biochemistry and Behavior, 73, 131-140.

Levine, S. (2001). Primary social relationships influence the development of the hypotalamic-pituitary-adrenal axis in the rat. Physiology and Behavior, 73, 255-260.

Levine, S., Haltmeyer, G.C., Karas, G.G., \& Denenberg, V.H., (1967). Physiological and behavioral effects of infantile stimulation. Physiology and Behavior, 2, 55-59.

Liu, D., Caldji, C., Sharma, S., Plotsky, P.M., \& Meaney, M.J. (2000). Influence of neonatal rearing conditions on stressinduced adrenocorticotropin responses and norepinepherine release in the hypotalamic paraventricular nucleus. Journal of Neuroendocrinology, 12, 5-12.

Liu, D., Diorio, J., Tannenbaum, B., Caldji, C., Francis, D., Freedman, A., Sharma S., Pearson, D., Plotsky, P.M., \& Meaney, M.J. (1997). Maternal care, hippocampal glucocorticoid receptors, and hypotalamic-pituitary-adrenal response to stress. Science, 277, 1659-1662.

Lucion, A.B., Pereira, F.M., Winkelman, E.C., Sanvitto, G.L., \& Anselmo-Franci J.A. (2003). Neonatal handling reduces the number of cells in the locus coeruleus of rats. Behavioral Neuroscience, 117, 894-903.

Macri, S., Mason, G.J., \& Wurbel, H. (2004). Dissociation in the effects of neonatal maternal separations on maternal care and the offspring's HPA and fear responses in rats. European Journal of Neuroscience, 20, 1017-1024.

Madruga, C., Xavier, L.L., Achaval, M., Sanvitto, G.L., \& Lucion, A.B. (2006). Early handling, but not maternal separation, decreases emotional responses in two paradigms of fear without changes in mesolimbic dopamine. Behavioural Brain Research, 166, 241-246. 
Matthews, K., Wilkinson, L.S., \& Robbins, T.W. (1996). Repeated maternal separation of preweanling rats attenuates behavioral responses to primary and conditioned incentives in adulthood. Physiology and Behavior, 59, 1, 99-107.

Meaney, M.J., Diorio, J., Francis, D., Widdowson, J., LaPlante, P., Caldji, C., Sharma, S., Seckl, J.R., \& Plotsky, P.M. (1996). Early environmental regulation of forebrain glucocorticoid receptor gene expression: implications for adrenocortical responses to stress. Developmental Neuroscience, 18, 49-72.

Moore, C.L. (1992). The role of maternal stimulation in the development of sexual behavior and its neural basis. Annals of the New York Academy of Sciences, 662, 160-177.

Numan, M., \& Insel, T.R. (2003). The neurobiology of parental behavior. New York: Springer.

Padoin, M.J., Cadore, L.P., Gomes, C.M., Barros, H.M., \& Lucion, A.B. (2001). Long-lasting effects of neonatal stimulation on the behavior of rats. Behavioral Neuroscience, 115, 1332-1340.

Pauk, J., Khun, C.M., Field, T.M., \& Schanberg, S.M. (1986). Positive effects of tactile versus kinesthetic or vestibular stimulation on neuroendocrine and ODC activity in maternally-deprived rat pups. Life Sciences, 39, 2081-2078.

Raineki, C., Szawka, R.E., Gomes, C.M., Lucion, M.K., Barp, J., Belló-Klein, A., Franci, C.R., Anselmo-Franci, J.A., Sanvitto, G.L., \& Lucion, A.B. (2008). Effects of neonatal handling on central noradrenergic and nitric oxidergic systems and reproductive parameters in female rats. Neuroendocrinology, 87, 151-159.
Raineki, C., de Souza, M.A., Szawka, R.E., Lutz, M.L., de Vasconcellos, L.F., Sanvitto, G.L., Izquierdo, I., Bevilaqua, L.R., Cammarota, M., \& Lucion, A.B. (2009). Neonatal handling and the maternal odor preference in rat pups: involvement of monoamines and cyclic AMP response element-binding protein pathway in the olfactory bulb. Neuroscience, 159, 31-38.

Schanberg, S.M., Evoniuk, G., \& Kuhn, C.M. (1984). Tactile and nutritional aspects of maternal care: specific regulators of neuroendocrine function and cellular development. Proceedings of the Society for Experimental Biology and Medicine, 175, 135-146.

Scott, J.P. (1962). Critical periods in behavioral development. Science, $138,949-958$.

Severino, G.S., Fossati, I.A.M., Padoin, M.J., Gomes, C.M., Trevisan, L., Sanvitto, G.L., Franci, C.R., Anselmo-Franci, J.A., \& Lucion, A.B. (2004). Effects of neonatal handling on the behavior and prolactin stress response in male and female rats at various ages and estrous cycle phases of females. Physiology and Behavior, 81, 489-498.

Stern, J.M., \& Johnson, S.K. (1990). Ventral somatosensory determinants of nursing behavior in Norway rats: I. Effects of variations in the quality and quantity of pup stimuli. Physiology and Behavior, 47, 993-1011.

Van Oers, H.J.J., de Kloet, E.R., \& Levine, S. (1999). Persistent effects of maternal deprivation on HPA regulation can be reversed by feeding and stroking, but not by dexamethasone. Journal of Neuroendocrinology, 11, 581-588. 